Revue d'histoire du XIXe siècle

Société d'histoire de la révolution de 1848 et des

révolutions du XIXe siècle

$44 \mid 2012$

L'Italie du Risorgimento. Relectures

\title{
André LÉO, Aline-Ali, nouvelle édition présentée et annotée par Cecilia Beach, Caroline Granier et Alice Primi, Chauvigny
}

APC éditions/Association André Léo, Cahiers du Pays Chauvinois, $\mathrm{n}^{\circ} 41$, 2011, 184 p. ISBN : 978-2-909165-99-8. 20 euros.

Nicole Edelman

\section{(2) OpenEdition}

Journals

Édition électronique

URL : http://journals.openedition.org/rh19/4276

DOI : $10.4000 /$ rh 19.4276

ISSN : $1777-5329$

Éditeur

La Société de 1848

Édition imprimée

Date de publication : 30 septembre 2012

Pagination : 213

ISSN : 1265-1354

Référence électronique

Nicole Edelman, «André LÉO, Aline-Ali, nouvelle édition présentée et annotée par Cecilia Beach,

Caroline Granier et Alice Primi, Chauvigny », Revue d'histoire du XIXe siècle [En ligne], 44 | 2012, mis en

ligne le 16 octobre 2012, consulté le 22 septembre 2020. URL : http://journals.openedition.org/

rh19/4276 ; DOI : https://doi.org/10.4000/rh19.4276

Ce document a été généré automatiquement le 22 septembre 2020.

Tous droits réservés 


\section{André LÉO, Aline-Ali, nouvelle édition présentée et annotée par Cecilia Beach, Caroline Granier et Alice Primi, Chauvigny}

APC éditions/Association André Léo, Cahiers du Pays Chauvinois, $n^{\circ} 41$, 2011, 184 p. ISBN : 978-2-909165-99-8. 20 euros.

Nicole Edelman

\section{RÉFÉRENCE}

André LÉO, Aline-Ali, nouvelle édition présentée et annotée par Cecilia Beach, Caroline Granier et Alice Primi, Chauvigny, APC éditions/Association André Léo, Cahiers du Pays Chauvinois, $\mathrm{n}^{\circ}$ 41, 2011, 184 p. ISBN : 978-2-909165-99-8. 20 euros.

1 Léodile Béra-Champseix (1824-1900), qui a pour pseudonyme André Léo, est une romancière et une essayiste engagée pour l'émancipation des femmes et la liberté individuelle. Écrite dans la deuxième moitié du XIX siècle, son œuvre est encore peu connue du grand public mais elle est lentement rééditée et sa lecture ne déçoit pas, bien au contraire. Dans les années 1860, André Léo publie 12 œuvres de fiction et dans chacune, elle explore une question féministe. Deux romans ont déjà fait l'objet d'une nouvelle publication, Un mariage scandaleux (en 2000) et Marianne (en 2006), auxquels il faut ajouter la biographie consacrée à l'auteure par Alain Dalotel en $2004^{1}$.

2 La réédition d'Aline-Ali s'inscrit dans cette dynamique. Les commentaires et les annotations de Caroline Granier et Alice Primi sont fort précieux pour ceux qui ignoreraient le contexte politique et social au moment où le roman paraît (1868). Alice Primi propose en ouverture une présentation d'André Léo " auteure engagée dans les enjeux de son temps » où elle analyse la difficulté d'être une femme démocrate sous le Second Empire au moment où «la question des femmes" est au cœur des débats 
démocratiques. Cecilia Beach expose ensuite la force du roman et de la fiction dans l'engagement politique d'André Léo en montrant qu'Aline-Ali est un roman féministe anti-proudhonien. À la fin du roman, Caroline Granier s'interroge, de manière provocatrice : Aline-Ali, un roman queer ? Elle y souligne - avec André Léo - les limites d'une subversion par le travestissement. Aline se déguise en effet longuement en homme (Ali) dans le roman, mettant ainsi au jour la fragilité des normes sans pour autant toucher par cette posture aux fondements de l'ordre social et politique. Une courte biographie d'André Léo clôt l'ouvrage.

Dans le format original des Cahiers $(20 \mathrm{~cm} \times 21 \mathrm{~cm})$ et dans une belle présentation, la lecture d'Aline-Ali m'a donné de multiples plaisirs, celui d'une belle écriture, celui d'une véritable histoire dont on a envie de connaitre la suite et aussi celui d'une forte critique de la domination masculine qui fait bien des échos à notre situation contemporaine.

\section{NOTES}

1. Alain Dalotel, André Léo (1824-1900). La Junon de la Commune, Chauvigny, Association des publications chauvinoises, 2004. 